\title{
Teaching Review on Approach for Emergency Intubation
}

\author{
Adel Hamed Elbaih $M D^{1,2^{*}}$ and Mohammed Eyad Marrie ${ }^{3}$ \\ ${ }^{1}$ Associate Professor of Emergency Medicine, Sulaiman Al-Rajhi University, Clinical Medical Science, Saudi \\ Arabia \\ ${ }^{2}$ Associate Professor of Emergency Medicine, Faculty of Medicine, Suez Canal University, Ismailia, Egypt \\ ${ }^{3}$ Emergency Medicine in Clinical Medical Science Department, College of medicine, Sulaiman Al-Rajhi \\ University, Saudi Arabia
}

\begin{abstract}
Background: Physicians commonly secure the airway with the aid of rapid sequence intubation (RSI)-also called drug assisted intubation- in an acutely unstable patient. As these patients are at high risk of aspiration the RSI is especially useful as it combines medications and techniques to minimize this risk. In addition, the RSI also helps to reduce the potential adverse effects of airway manipulation. Therefore, we aim to look into RSI for both medical students and new physicians face in the recognition, diagnosis and management of maintaining a secure patent airway.
\end{abstract}

Targeted population: Emergency Physicians needs of teaching protocol of RSI.

Aim of the study: Appropriate approach of RSI by training protocol to Emergency Physicians. Based on practice gaps for preventive death and adverse long-term complications of airway problems.

Methods: Collection of all possible available data about the RSI with its complications in the Emergency department (ED). By many research questions to achieve these aims so a midline literature search was performed with the keywords "critical care", "emergency medicine", "principals of airway management", "Endotracheal Intubation", "RSI" Literature search from Emergency Room (ER) view included an overview of with recent definition, causes and recent therapeutic strategies.

Results: All studies introduced that the initial diagnosis of airway problems and its management is a lifesaving conditions that face patients of in ED and intensive care unit (ICU).

\begin{abstract}
Conclusion: RSI guidelines will help resolve much of the guesswork that many primary care providers have to consider when evaluating cases who have sustained some form of maintaining secure patent airway troubles. Clinicians can say that the preoxygenation is very important to prevent Hypoxemia and its complication, and the importance of the rapid sequence intubation.
\end{abstract}

\section{Keywords}

RSI, Airway Management, Emergency physicians, Skill approach

\section{Introduction}

Physician commonly use rapid sequence intubation (RSI) to secure the airway in an acutely unstable patient. RSI begins with the administration of an induction agent followed quickly by a neuromuscular blocking agent to create an optimal intubating condition and reduce the time the airway is left unprotected [1].

$\mathrm{RSI}$ assumes the patient is at risk for aspiration of stomach contents and combines medications and techniques to minimize this risk. In addition, the RSI also helps to reduce the potential adverse effects occurring with airway manipulation [2].

\section{Incidence of hypoxemia}

Fall of $\mathrm{O} 2$ saturation of less than $90 \%$ occurs during rap- id sequence intubation in 15 (15\%) of 101 patients suffering from trauma who were managed by anesthesiology staff and in $19(18 \%)$ of 99 patients taken care for by emergency physicians [3].

*Corresponding author: Dr. Adel Hamed Elbaih, Associate Professor of Emergency Medicine, Sulaiman Al-Rajhi University, Clinical Medical Science, Saudi Arabia; Associate Professor of Emergency Medicine, Suez Canal University Ismailia, Egypt, Tel: 00201154599748

Accepted: November 11, 2020

Published online: November 13, 2020

Citation: Elbaih AH, Marrie ME (2020) Teaching Review on Approach for Emergency Intubation. Sch J Emerg Med Crit Care $4(1): 85-89$

Copyright: (C) 2020 Elbaih AH, et al. This is an open-access article distributed under the terms of the Creative Commons Attribution License, which permits unrestricted use, distribution, and reproduction in any medium, provided the original author and source are credited. 
In the 54 patients with complete records, 31 (57\%) showed evidence of desaturation during the rapid sequence intubation procedure. Twenty-six (84\%) of these 31 patients had initial $\mathrm{SpO}_{2}$ values greater than or equal to $90 \%$ before administration of rapid sequence intubation medications [4].

In this paper, we aim to review the essential concepts and techniques required to perform RSI in an emergency setting outside the operating room. The medications administered for emergency RSI. In addition, we will address one of the key problems that could be encountered during RSI that is Hypoxemia [5].

\section{Problem}

Hypoxemia defined as a low arterial oxygen supply, and it is the frequently encountered problem occurring after the RSI (Rapid sequence intubation), which usually could have been avoided by properly following all the required step.

\section{Why this is a problem?}

A plethora of physicians tend to forget to perform pre-oxygenation prior to RSI due to the fact that they are under stress and their desire to save the patient as fast as possible, despite the fact that studies shows the importance of the pre-oxygenation step, for this point patient undergo hypoxemia. We will see later how to do it and how it will affect the patient.

\section{Why is this study necessary?}

Because it's a frequently encountered problem, and there is a solution to it we can lead us to avoid a lot of complications and risks of hypoxemia, and save more time and lives.

\section{Research question}

Can we avoid the post RSI hypoxemia? How we can do this?

\section{Methods}

This section includes Collection of all possible available data about the RSI with its complications in the Emergency department (ED). By many research questions to achieve these aims so a midline literature search was performed with the keywords "critical care", "emergency medicine", "principals of airway management", "Endotracheal Intubation", "RSI" Literature search from Emergency Room (ER) view included an overview of with recent definition, causes and recent therapeutic strategies. All studies introduced that the initial diagnosis of airway problems and its management is a lifesaving conditions that face patients of in ED and intensive care unit (ICU).

So the main aims and outcome of the study: Initial assessment and evaluate patient's presentation to recognize potentially life-threatening conditions and to convey life-saving treatment especial with airway problems so the key note here is that initial diagnosis in suspected cases with initial treatment by appropriate approach of RSI with training protocol to Emergency Physicians. Based on practice gaps for preventive death and adverse long-term complications of airway problems.
While searching for this study, the Royal College of Emergency Medicine, Medline website and PubMed were searched for relevant the search was restricted to articles published between 1960 and 2011.

The databases were searched using the relevant terms, including all subheadings, and this was combined with a keyword search. Search words included "Difficult intubation" 'Airway Management', 'cardiac arrest obstructed airway', 'RSI' and 'resuscitation management' 'drug assisted ventilation'. The search was also limited to humans and the English language. The National Library for Health and the National Guidelines Clearing House were also searched for relevant guidelines and reviews.

\section{Definition}

RSI is the effective simultaneous administration of an induction agent and a neuromuscular blocking agent to induce unconsciousness and paralysis to facilitate rapid tracheal intubation. The technique was developed to maximize the chances of successful intubation and to reduce the risk of aspiration. It is essential that maximal preoxygenation and hemodynamic optimization precede drug administration [6].

Preoxygenation is a fundamental step of RSI aiming to creates a large intrapulmonary reservoir of oxygen that allows patients to tolerate a period of apnea without clinically significant oxygen desaturation. In patients with high risk for aspiration, bag-mask ventilation is avoided by all means during the interval between drug administration and tracheal tube placement, to minimizing gastric insufflation and reducing the risk of aspiration. RSI has been shown to be associated with increased first pass success like (successful tracheal tube placement on first attempt) and reduced incidence of complications. Despite this, since the induction agent is administered in a rapid fashion, critically ill patients are at highly vulnerable to develop hypotension. But this risk can be optimized by proper choice of induction medication and by stabilizing the patient's cardiovascular status with crystalloids, blood products, vasopressors, or inotropes as appropriate prior to RSI [7].

\section{Indications}

A plethora studies have demonstrated the benefits of RSI in the critically ill patient, with improved first pass success and reduced incidence of complications. In addition, RSI could be the favored approach in patients with anatomically difficult airway if the incubator has the expertise to maintain the gas exchange, either by successful intubation or with the aid of rescue device. When performing RSI in a patient with an expected difficult airway, the physician must prepare and have all the equipment necessary to restore oxygenation at his disposal. Such equipment generally includes a bag, mask device, extraglottic airway like (laryngeal mask airway), and tools for a surgical airway [8].

\section{Contraindications}

There is no absolute contraindication to RSI only relative ones. The most important contraindication to RSI is anticipation of difficult or impossible rescue oxygenation. In patients 
Table 1: Rapid sequence intubation induction agents for adults [10].

\begin{tabular}{|c|c|c|c|c|c|}
\hline Drug name & Class & Benefits & Contraindications & Notes & Dose \\
\hline Etomidate & $\begin{array}{l}\text { Imidazole } \\
\text { derivative }\end{array}$ & $\begin{array}{l}\text { Excellent sedation with } \\
\text { little hypotension }\end{array}$ & $\begin{array}{l}\text { Known to suppress adrenal } \\
\text { cortisol production }\end{array}$ & $\begin{array}{l}\text { Use cautiously if patient } \\
\text { has sepsis; initial dose of } \\
\text { glucocorticoid may be needed }\end{array}$ & $0.3 \mathrm{mg} / \mathrm{kg}$ \\
\hline Ketamine & $\begin{array}{l}\text { Phencyclidine } \\
\text { derivative, } \\
\text { dissociative } \\
\text { anesthetic }\end{array}$ & $\begin{array}{l}\text { Stimulates } \\
\text { catecholamine release } \\
\text { Bronchodilation }\end{array}$ & $\begin{array}{l}\text { Use in patients with elevated } \\
\text { ICP or elevated blood pressure } \\
\text { is controversial }\end{array}$ & $\begin{array}{l}\text { May be an excellent } \\
\text { induction agent for patients } \\
\text { with bronchospasm, septic } \\
\text { shock, AND hemodynamic } \\
\text { compromise }\end{array}$ & 1 to $2 \mathrm{mg} / \mathrm{kg}$ \\
\hline Midazolam & Benzodiazepines & $\begin{array}{l}\text { Potent dose- related } \\
\text { amnesic properties }\end{array}$ & $\begin{array}{l}\text { Dose-related myocardial } \\
\text { depression can result in } \\
\text { hypotension }\end{array}$ & Frequently underdosed & 0.2 to $0.3 \mathrm{mg} / \mathrm{kg}$ \\
\hline Propofol & $\begin{array}{l}\text { Alkylphenol } \\
\text { derivative }\end{array}$ & Bronchodilation & $\begin{array}{l}\text { No absolute contraindications } \\
\text { Dose-related hypotension }\end{array}$ & & 1.5 to $3 \mathrm{mg} / \mathrm{kg}$ \\
\hline $\begin{array}{l}\text { Thiopental } \\
\text { sodium }\end{array}$ & $\begin{array}{l}\text { Ultrashort- acting } \\
\text { barbiturate }\end{array}$ & $\begin{array}{l}\text { Cerebroprotective } \\
\text { and anti- convulsive } \\
\text { properties }\end{array}$ & $\begin{array}{l}\text { Potent venodilator and } \\
\text { myocardial depressant; can } \\
\text { cause hypotension Relatively } \\
\text { contraindicated in reactive } \\
\text { airway disease due to } \\
\text { histamine release }\end{array}$ & $\begin{array}{l}\text { May not be commercially } \\
\text { available. Rarely used. }\end{array}$ & 3 to $5 \mathrm{mg} / \mathrm{kg}$ \\
\hline
\end{tabular}

Table 2: Neuromuscular Blocking Agents used in RSI [11].

\begin{tabular}{|l|l|l|l|}
\hline Agent & Adult intubation IV dose & onset & duration \\
\hline Rocuronium (intermediate/long) & $1 \mathrm{milligram} / \mathrm{kg}$ & $1-3 \mathrm{~min}$ & $30-45 \mathrm{~min}$ \\
\hline Vecuronium (intermediate/long) & $0.08-0.15 \mathrm{milligram} / \mathrm{kg}$ & $2-4 \mathrm{~min}$ & $25-40 \mathrm{~min} 60-120 \mathrm{~min}$ \\
& $0.15-0.28 \mathrm{milligram} / \mathrm{kg}$ (high-dose protocol) & & \\
\hline Succinylcholine & $1.5 \mathrm{milligrams} / \mathrm{kg}$ & $45-60 \mathrm{~s}$ & $5-9 \mathrm{~min}$ \\
\hline
\end{tabular}

Table 3: The Seven Ps of rapid sequence intubation.

\begin{tabular}{|l|l|}
\hline Action & Time \\
\hline Preparation & 10 minutes before intubation \\
\hline Preoxygenation & 5 minutes before intubation \\
\hline Pre-intubation optimization & $\begin{array}{l}3 \text { minutes before intubation (may be longer depending on necessary interventions and } \\
\text { time available) }\end{array}$ \\
\hline Paralysis with induction & Induction \\
\hline Protection & 30 seconds after induction \\
\hline Placement (Intubation) & 45 seconds after induction \\
\hline Post-intubation management & 60 seconds after induction \\
\hline
\end{tabular}

who cannot tolerate apnea like (profound hypoxemia or metabolic acidosis is present), neuromuscular blockade may be undesirable and an awake intubation approach (e.g. use of topical anesthesia and light sedation) preferred in order to minimize the possibility of quick deterioration [9-12] (Table 1, Table 2 and Table 3) (Figure 1).

\section{Step 1: Preparation}

The initial step in RSI is to gather and prepare the necessary equipment and all essential supplies including medications which could be used for an emergency intubation including oxygen, suction, bag-valve mask (BVM), laryngoscope with its blades, endotracheal (ET) tubes with a stylet varying sizes some larger and other smaller than the anticipated ET size.

In addition, all resuscitation equipment, for rescue maneuvers (e.g. laryngeal mask airways or cricothyrotomy) which is utilized in situation where intubation fails following the Can't Intubate, Can't Ventilate American Society of Anesthesiologists (ASA) guidelines [13].

\section{Step 2: Preoxygenation}

Oxygen is crucial for Survival and it is not acceptable to forget so this step should be performed during the preparation phase. The aim of preoxygenation is to displace the 


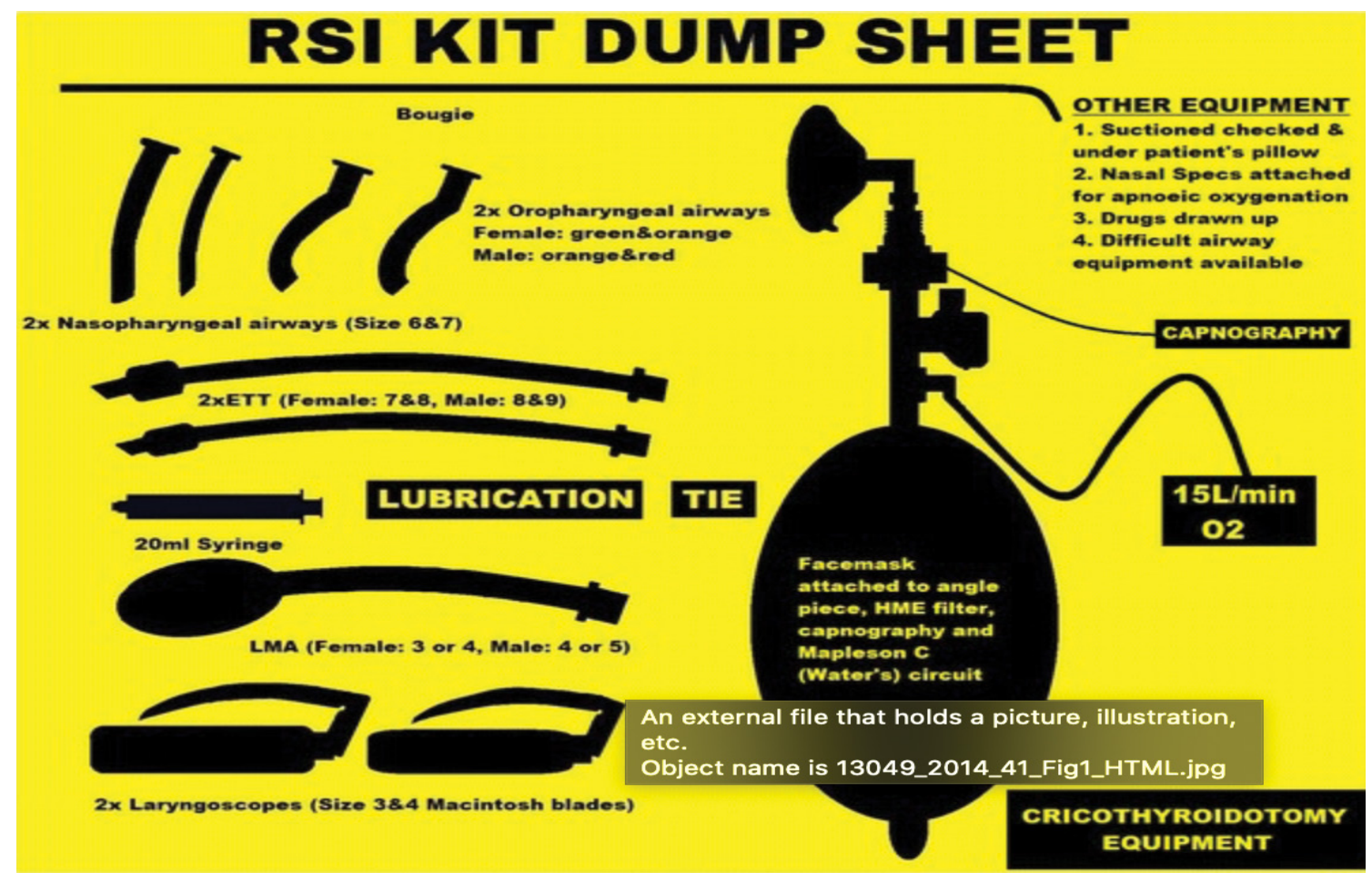

Figure 1: Rapid sequence intubation kit [12].

wasteful nitrogen in patient's functional residual capacity with $\mathrm{O} 2$ also known as "nitrogen wash-out oxygen wash-in" (Denitrogenation).

This could be done within $3=5$ minutes by making the patient breathe $100 \% \mathrm{O} 2$ with the aid of tight-fitting facemask or incase if shortage of time with a 4 vital capacity breaths [14].

\section{Step 3: Pretreatment}

In addition, we introduce the Ancillary medications during the pretreatment phase to lessen the negative physiologic responses to intubation.

For optimal results, these drugs should be administered prior to induction agent by three minutes, but this not always feasible.

In emergency situation the pretreatment and preoxygenation phases of RSI can (almost always) performed simultaneously [15].

\section{Step 4: Paralysis with induction}

The desired Paralysis is achieved by the rapid IV administration in succession of the induction agent and the NMB. The choice of the right sedative agent is based on multiple factors: the clinical scenario, including patient factors such as (cardiorespiratory status, neurologic status, allergies, comorbidity) and the physicians experience/training in addition to institutional factors, also the characteristics of the agent [16].

\section{Step 5: Protection and positioning}

A key point is to Position the head and neck to obtain an ideal view of the glottic opening for conventional laryngosco- py by aligning the three axes: Oral, pharyngeal, and laryngeal. Which is possible by extending and elevating the neck to achieve the "sniffing the morning air", of course such maneuvering should only be performed if there is no contraindication such as cervical injury [17].

\section{Step 6: Placement of the endotracheal tube in the trachea}

As the jaw muscles becomes flaccid and relaxed due to the paralytics, marking the starting time to initiate the intubation by standard methods.

Also after the placement of the tube its mandatory to confirm that it sits in the right spot [18].

\section{Step 7: Post intubation management}

As the ET tube placement had been confirmed, it must be secured tightly to it place. A CXR is performed to check for proper ET tube placement in addition to evaluate and monitor the pulmonary status to detect any deterioration or complications of RSI.

Continued sedation and analgesia, sometimes with paralysis as well as cardiopulmonary monitoring, is indicated as long as the patient requires advanced airway support [19].

\section{Conclusion}

RSI remains incomplete until the properly placed ETT is secured. Several techniques are commonly used to secure the tube, including taping, tying, and using proprietary tube-holders. The technique employed for ED airway management should be readily available, easy to apply, and secure. A post-procedural chest radiograph is obtained to con- 
Table 4: Emergency intubation evaluation checklist.

\begin{tabular}{|c|c|c|c|}
\hline Prepare Patient & Prepare Equipment & Prepare for Difficulty & Prepare Team \\
\hline $\begin{array}{l}\text { Check: } \\
\text { - } \text { Pulse oximeter } \\
\text { - } \text { BP (every } 2 \mathrm{~min} \text { ) } \\
\text { - } \text { Capnography } \\
\text { - } \text { ECG } \\
\text { Optimal positioning: } \\
\text { - } \text { Ramping in obese patient. } \\
\text { - } 30^{\circ} \text { head up for head injury } \\
\text { - Neck immobilization for } \\
\text { suspected C-spine injury } \\
\text { Good IV access with fluid running. } \\
\text { Adequate preoxygenation. }\end{array}$ & $\begin{array}{l}\text { Check for Oxygen Supply. } \\
\text { Check for Airway equipment: } \\
\text { 1. Facemask } \\
\text { 2. Airway adjuncts } \\
\text { 3. Self-inflating bag } \\
\text { 4. } 2 \text { laryngoscopes } \\
\text { 5. Appropriate ET tubes } \\
\text { 6. Suction } \\
\text { Check for Drugs: } \\
\text { 1. RSI drugs } \\
\text { 2. Vasopressor } \\
\text { 3. Maintenance of sedation } \\
\text { and paralysis }\end{array}$ & $\begin{array}{l}\text { Prepare for difficult airway if } \\
\text { anticipated: } \\
\text { 1. VDO laryngoscope } \\
\text { 2. LMA } \\
\text { 3. Cricothyroidotomy kit } \\
\text { Difficult airway trolley present. }\end{array}$ & 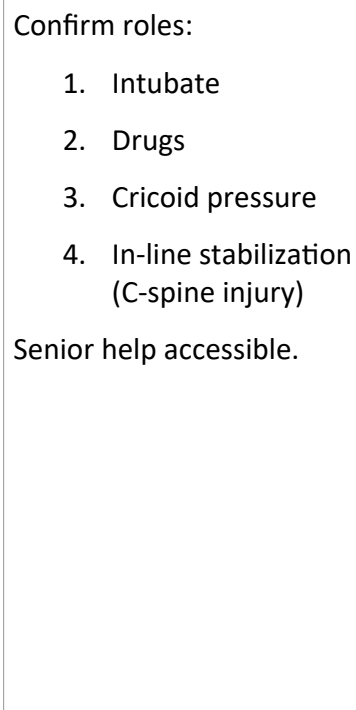 \\
\hline
\end{tabular}

firm depth of tube placement and to evaluate for evidence of barotrauma as a consequence of positive pressure ventilation. Finally, in this review we can say that the preoxygenation is very important to prevent the Hypoxemia and its complication, and the importance of the rapid sequence intubation. At the end, proceed RSI when all checks confirmed in ED. However, it a different airway is anticipated a fiberoptic awake intubation or video laryngoscopeappears more likely than the RSI with direct laryngoscopy if the indication is only the risk of aspiration and the patient is stable in cardio pulmonary context (Table 4).

\section{References}

1. Tintinalli, Judith E (2019) Tintinallis emergency medicine: A comprehensive study guide. ( $9^{\text {th }}$ edn), McGraw-Hill Education.

2. Elbaih AH, Housseini AM (2018) Validity of shock index, modified shock index, central venous pressure, and inferior vena cava collapsibility index in evaluation of intravascular volume among hypovolemic Egyptian patients. American Journal of Diagnostic Imaging 4: 5-13.

3. Davis Daniel P, Dunford James V, Poste Jennifer C, et al. (2004) The impact of hypoxia and hyperventilation on outcome after paramedic rapid sequence intubation of severely head-injured patients. The Journal of Trauma: Injury, Infection, and Critical Care 57: 1-10.

4. Elbaih AH, Taha M, Elsakaya MS, et al. (2019) Assessment of cardiopulmonary resuscitation knowledge and experiences between emergency department nurses hospital pre and post basic life support training course, Egypt. Annals of Medical Research 26: 2320-2327.

5. Elbaih AH (2017) Different types of triage. Arşiv Kaynak Tarama Dergisi. Archives Medical Review Journal 26: 441-467.

6. M Helm, G Kremers, L Lampl, et al. (2012) Incidence of transient hypoxia during pre-hospital rapid sequence intubation by anaesthesiologists. Acta Anaesthesiologica Scandinavica 57: 199-205.

7. Elbaih AH, Basyouni FH (2020) Teaching approach of primary survey in trauma patients. Int J Intern Emergency Medicine.

8. Mace Sharon Elizabeth (2008) Challenges and advances in intu- bation: Rapid sequence intubation. Emerg Med Clin North Am 26: 1043-1068.

9. Elbaih AH, Mousa MA (2020) Review article: Teaching review on approach of esophageal intubation as complications in emergency airway management. American Journal of Surgical Case Reports 2: 2-6.

10. Neilipovitz David T, Edward T Crosby (2007) No evidence for decreased incidence of aspiration after rapid sequence induction. Can J Anaesth 54: 748-764.

11. (2020) Rapid sequence intubation. Background, indications, contraindications.

12. Weingart SD, Levitan RM (2012) Preoxygenation and prevention of desaturation during emergency airway management. Ann Emerg Med 59: 165-175.

13. Lee BJ, Kang JM, Kim DO (2007) Laryngeal exposure during laryngoscopy is better in the 25 degrees back-up position than in the supine position. Br J Anaesth 99: 581-586.

14. Elbaih AH, Elsayed ZM, Ahmed RM, et al. (2019) Sepsis patient evaluation emergency department (SPEED) score \& mortality in emergency department sepsis (MEDS) score in predicting 28-day mortality of emergency sepsis patients. Chinese Journal of Traumatology 22: 316-322.

15. Cattano D, Melnikov V, Khalil Y, et al. (2010) An evaluation of the rapid airway management positioner in obese patients undergoing gastric bypass or laparoscopic gastric banding surgery. Obes Surg 20: 1436-1441.

16. Elbaih AH, Alissa ZK (2020) The Effect of cardiopulmonary resuscitation quality on cardiac arrest outcome. Journal Emergency Medicine and Care.

17. Tanoubi I, Drolet P, Donati F (2009) Optimizing preoxygenation in adults. Can J Anaesth 56: 449-466.

18. Taha M, Elbaih A (2017) Review article, pathophysiology and management of different types of shock. NMJ 6: 14-39.

19. Robinson A, Ercole A (2012) Evaluation of the self-inflating bagvalve-mask and non-rebreather mask as preoxygenation devices in volunteers. BMJ Open 2: e001785. 